\title{
Integrated Solid-state Sensors Monitoring Water Quality for the Next Generation of Wireless Sensor Networks
}

\author{
Serge Zhuiykov ${ }^{1}$, Eugene Kats ${ }^{1}$ \\ ${ }^{1}$ CSIRO, Materials Science and Engineering Division, 37 Graham Road, Highett, VIC. 3190, Australia, \\ Corresponding author's e-mail address: serge.zhuiykov@csiro.au
}

\begin{abstract}
:
This research has been dedicated to the development of solid-state sensors for on-line-real-time monitoring of water quality parameters such as $\mathrm{pH}$ and dissolved oxygen (DO), dissolved organic carbon (DOC) at relatively high spatial resolutions. It has been established that the next generation of wireless sensor networks can be successfully coupled with accurate, inexpensive, robust and miniaturised solid-state sensors based on the concept of thin- or thick-film semiconductor sensing electrodes (SE), which successfully overcomes the challenges associated with bio-fouling.
\end{abstract}

Key words: Solid-state, pH, DO, E-tongue, Wireless sensor networks

\section{Introduction}

With increase of urbanization of our society and climate change, water pollution problems have been becoming more complex, requiring complicated continuous on-line monitoring and multi-stage treatment process. Traditional methods of water quality analysis, which involves the manual collection of water samples at various locations and at different times, followed by returning to the laboratory and undertaking a range of analytical techniques in order to characterize the water, are no longer considered efficient [1]. This is because of the relatively high labour costs as well as the costs associated with maintaining a laboratory equipped with a suite of complex analytical equipment. In addition the need for real-time data/information on source (or catchment) water quality has become more important as it enables critical decisions, around environmental impacts, along with water treatment and management prior to distribution to the population to be made. This creates a new paradigm in water quality sensing as the information has to be collected and transferred to some data repository where it can be analyzed and presented for decision making in a relatively short time frame. Therefore, if accurate measurement of water quality parameters such as $\mathrm{pH}$, DO, DOC, temperature, conductivity, turbidity etc. is required at different catchment depths with high spatial resolution, where the measuring instruments are likely to be part of wireless distributed sensor network, then robust, miniature, solid-state, inexpensive sensors like those presented below in Fig. 1, are the preferable.

\section{Results and Discussion}

A complication in the sensor scenario for catchment source water is that the water catchment area of most Australian major cities is comparable to that of the capital cities which they serve. For example, a satellite image of the one of the Australian capital cities; Brisbane, which has a population over $2.0 \mathrm{M}$, is presented in Fig. 2A, along with its major water catchment, Lake Wivenhoe. From the image of the Lake Wivenhoe catchment area, it is clear that implementation of water quality monitoring for the area will be very complex, given that area is approximately $250 \mathrm{~km}^{2}$, with complex geographical features such as streams and creeks, as well as mountainous ranges. The undertaking of the large scale monitoring task in this instance will require the incorporation of hundreds of reliable, inexpensive, miniature sensors distributed in a network such as that shown in Fig 2B. For ease of operation it is suggested that they be connected via $a$ wireless network, because of the convenience, costs and power needs associated with a wired network. In the current configuration, each node of the sensor network, such as that shown in Fig. $2 \mathrm{C}$ has a capacity to incorporate 6 to 8 sensors for monitoring parameters at different depths. The lack of reliable sensors with high bio-fouling resistance, and capability for combination with the next generation of sensor networks has been identified as a major limiting 
factor in implementing real-time on-line spatially distributed water quality monitoring [2-4].

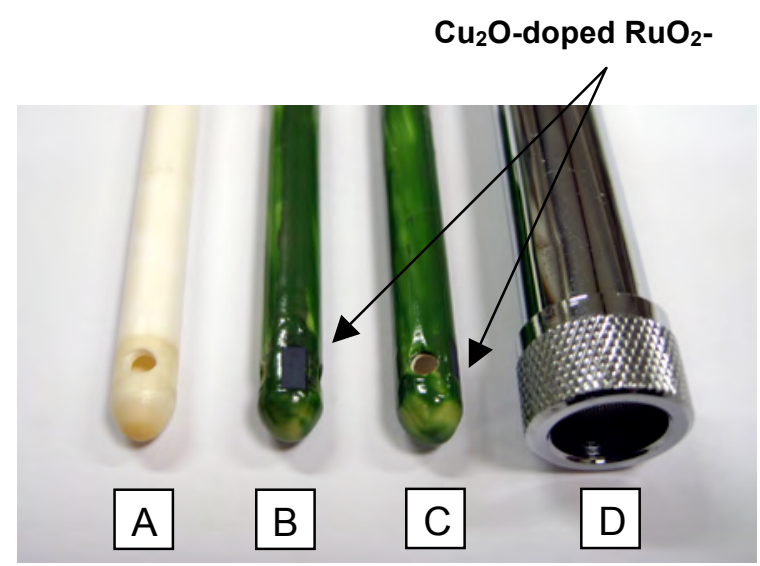

Fig. 1. Water quality sensor elements based on nano-structured $\mathrm{Cu}_{2} \mathrm{O}$-doped $\mathrm{RuO}_{2}-\mathrm{SE}$ : (A) alumina sensor tube; (B), (C) assembly of $\mathrm{Cu}_{2} \mathrm{O}$-doped $\mathrm{RuO}_{2-}$ SEs on the alumina tube covered by glaze protective layer and Ag/AgCl-RE incorporated inside of the sensor tube; (D) stainless steel protective sheet of the probe with built-in filter.

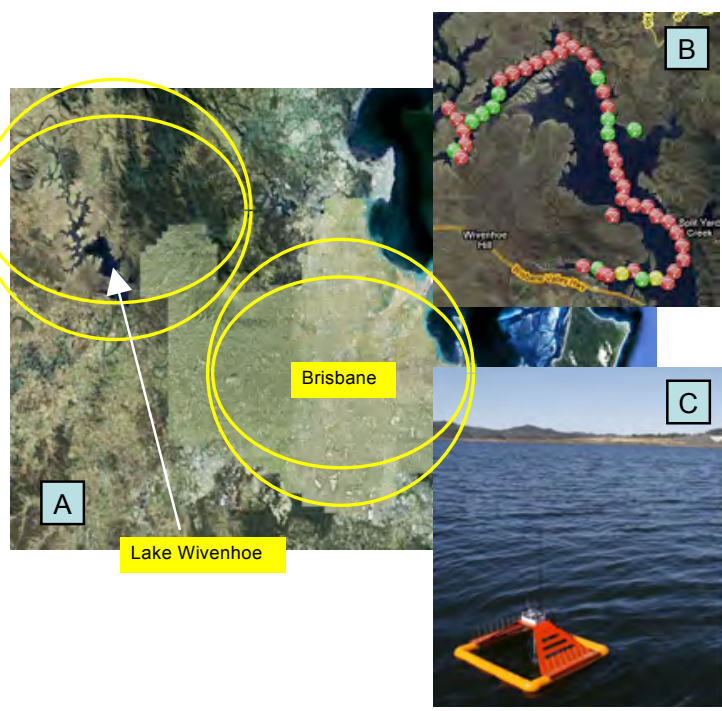

Fig. 2: Satellite image of the Australian capital city Brisbane and major Brisbane's water catchment (lake Wivenhoe) (A), installed distributed wireless sensors network on lake Wivenhoe (B) with an example of the sensors' node $(C)$.

DOC is generally defined as the organic matter that is able to pass through a filter, which removes material between $0.70 \mu \mathrm{m}$ and 0.22 $\mu \mathrm{m}$ in size. Determining the concentration of DOC in an aqueous solution, such as a sample of waste water or potable water, is important in diverse fields including pollution abatement and industrial processing situations. This is specifically important to Australia as a prolonged drought during the last decade resulted in increased adoption of recycled water to alleviate the environmental strain. CSIRO recently finished development of an inexpensive hand-help device for monitoring traces of DOC in the aqueous solutions [1]. The patented DOC sensor has innovatively been designed based on UV255 LED as the light source, reflecting mirror, and UV-sensitive photodiode as detector. The general view of the hand-held device together with the signal conditioning box and diagram exhibiting main components is shown in Fig. 3.
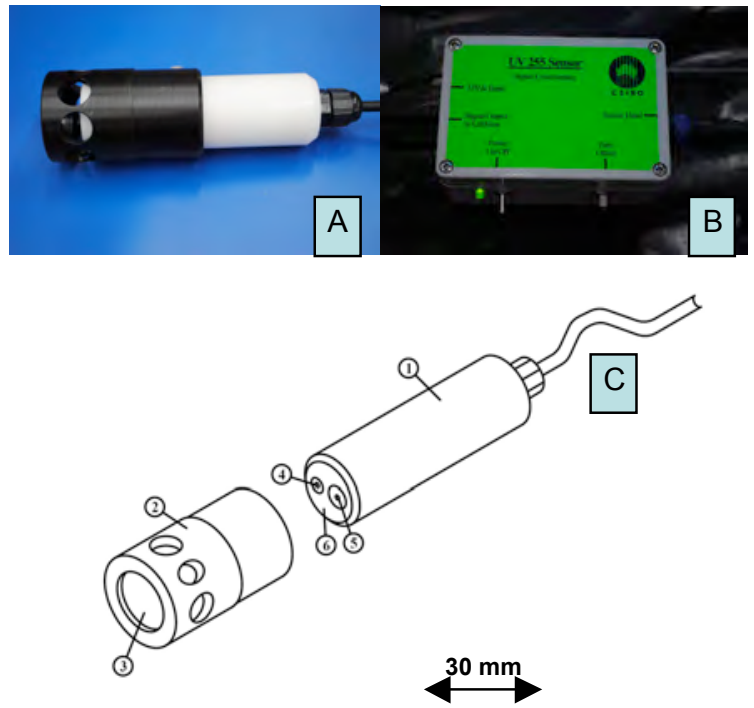

Fig. 3. DOC sensor with fixed outer sleeve (A), signal conditioning box (B) and diagram showing main components of the sensor (C).

The main body (1) incorporates a UV254 LED (4) as the light source and a UV photo-diode (5) as the detector, whilst the outer sleeve (2) houses a glass reflecting mirror (3). Sensor 1 has a front-surface mirror whereas sensor 2 has a back-surface mirror. The front-surface mirror can be cheaper glass whilst the backsurface mirror has to be UV-grade quartz. The mirror at the base of the movable sleeve reflects the UV signal back to the photo-diode and is secured to the sensor body using a plastic screw, which homes into a captive position each time the sleeve is refitted (this ensures that the path length of the absorption cell is constant). The UV photodiode has a current output which the pre-amp converts to a voltage and the AC signal is filtered and rectified to produce an analogue output voltage that is proportional to transmission intensity.

However, during field trials it was also established that turbidity does affect absorbance readings and therefore provides a false "high" concentration. Increase in turbidity (from 0 to $15 \mathrm{NTU}$ ) increases absorbance and 
needs compensation. Possible use of a 20 wavelength system could alleviate errors. Consequently, if DOC has to be measured in high turbidity solutions such as waste water, the testing solution has to pass through a $1 \mu \mathrm{m}$ filter prior to measurement. Therefore, the best analysis of the water can be achieved if the hand-held DOC sensor is used in conjunction with the turbidity sensor.

During the last few years the possibility to perform measurements of concentrations of a number of chemical species in complex solutions has resulted in a number of devices called "Electronic tongue" (E-tongue) for monitoring dissolved metal ions in complex solutions $[1,5]$.

\begin{tabular}{|c|c|c|c|}
\hline $\mathbf{N} / \mathbf{N}$ & $\begin{array}{c}\text { Contaminant } \\
\text { and unit } \\
\text { of measuremen } \\
\mathbf{t}\end{array}$ & $\begin{array}{c}\text { Acceptabl } \\
\text { e value in } \\
\text { raw water }\end{array}$ & $\begin{array}{c}\text { Acceptabl } \\
\text { e value in } \\
\text { drinking } \\
\text { water }\end{array}$ \\
\hline 1 & Arsenic (mg/L) & 0.01 & 0.01 \\
\hline 2 & Cadmium (mg/L) & 0.003 & 0.003 \\
\hline 3 & Lead (mg/L) & 0.05 & 0.01 \\
\hline 4 & $\begin{array}{c}\text { Chromium } \\
(\mathrm{mg} / \mathrm{L})\end{array}$ & 0.05 & 0.05 \\
\hline 5 & Zinc (mg/L) & 3.00 & 3.00 \\
\hline 6 & Copper (mg/L) & 1.0 & 1.0 \\
\hline 7 & $\begin{array}{c}\text { Mercury (total) } \\
(\mathrm{mg} / \mathrm{L})\end{array}$ & 0.001 & 0.001 \\
\hline 8 & $\begin{array}{c}\text { Magnesium } \\
(\mathrm{mg} / \mathrm{L})\end{array}$ & 150 & 150 \\
\hline
\end{tabular}

Table 1. Characteristics of solid-state electrodes of modern E-tongues for analysis of dissolved metals in complex solutions.

E-tongue is an analytical measuring device comprising an array of potentiometric chemical solid-sate sensors with relatively low selectivity albeit high sensitivity to several components of a solution (cross-sensitivity) and an advanced data processing engine such as pattern recognition or multivariate calibration. Within the last decade most E-tongues have proven to be very promising devices for rapid and precise simultaneous monitoring of dissolved heavy metals in different complex solutions. So far the most promising SE materials for construction of E-tongue for a particular application are the chalcogenide glass SE for monitoring $\left(\mathrm{Ag}^{+}, \mathrm{Tl}^{+}\right.$, $\mathrm{Cu}^{2+}, \mathrm{Pb}^{2+}, \mathrm{Cd}^{2+}, \mathrm{Hg}^{2+}, \mathrm{Fe}^{3+}, \mathrm{Cr}(\mathrm{VI})$ ), crystalline SE for monitoring ( $\mathrm{Fe}^{-}, \mathrm{Cl}^{-}, \mathrm{Br}^{-}, \mathrm{I}^{-}, \mathrm{CN}^{-}, \mathrm{CNC}^{-}$) and $\mathrm{PVC}$ plasticized SE for monitoring $\left(\mathrm{K}^{+}\right.$, $\mathrm{NH}_{4}^{+}, \mathrm{Ca}^{2+}, \mathrm{NO}_{3}{ }^{-}, \mathrm{Na}^{+}, \mathrm{Mg}^{2+}, \mathrm{Cl}^{-}, \mathrm{Zn}^{2+}, \mathrm{CO}_{3}{ }^{2-}$, $\mathrm{SO}_{4}{ }^{2-}, \mathrm{NO}_{2}{ }^{-}$), respectively. Table 1 summarizes technical information about these electrodes.

\section{Conclusions}

Nanostructured materials for reliable measurement of $\mathrm{pH}, \mathrm{DOC}$ and $\mathrm{DO}$, have shown great promise among other semiconductor thick film-SEs. The results obtained up to now suggest that structural and morphological modifications of nanostructured SEs present real possibilities for improving the selectivity, sensitivity, response and recovery rates of these sensors. The particular properties of grain boundaries and segregation layers of the complex nano-oxides with respect to their ionic and electronic defect concentrations offer many possibilities for modification of the current transport behavior, as well as the electrochemical characteristics of SEs and their interfaces. Based on this research it has become evident that increasing the efforts in basic or fundamental studies for better understanding of the sensing mechanisms becomes critical for progressing the development, and ultimate market availability of solid-state chemical water quality sensors, acceptable for practical use.

\section{Acknowledgements}

The work has been partially supported by the Research and development Program of CSIRO Sensors and Sensor Networks Transformation Capability Platform (SSN TCP) and CSIRO Materials Science and Engineering Division co-investment project "Nano Scale Sensor Networks".

\section{References}

[1] S. Zhuiykov, Solid-state sensors monitoring parameters of water quality for the next generation of wireless sensor networks, Sensors Actuators B: Chemical 161, 1-20 (2012); doi: 10.1016/j.snb.2011.10.078

[2] S. Zhuiykov, In situ FTIR study of oxygen adsorption on nanostructured $\mathrm{RuO}_{2}$ thin-film electrode, lonics 15, 5-7-512 (2009); doi: 10.1007/s11581-008-0294-0

[3] S. Zhuiykov, D. O'Brien, M. Best, Water quality assessment by an integrated multi-sensor based on semiconductor $\mathrm{RuO}_{2}$ nanostructures, Measurement Science Technology 20095201 (2009); doi: 10.1088/0957-0233/20/9/095201

[4] S. Zhuiykov, Potentiometric DO detection in water by ceramic sensor based on sub-micron $\mathrm{RuO}_{2}$ sensing electrode, lonics 15, 693-701 (2009); doi: 10.1007/s11581-009-0336-2

[5] S. Zhuiykov, E. Kats, V. Plashnitsa, N. Miura, Toward selective electrochemical "E-tongue": Potentiometric DO sensor based on sub-micron $\mathrm{ZnO}-\mathrm{RuO}_{2}$ sensing electrode, Electrochimica Acta 56, 5435-5442 (2011); doi: 10.1016/j.electacta.2011.01.062 